\title{
GAYA BAHASA SISWA KELAS VII A SMP N 21 BENGKULU UTARA TAHUN AJARAN 2016/2017 DALAM MENDONGENG
}

\author{
Rita Yuli Utami ${ }^{1}$, Suryadi ${ }^{2}$, dan Irma Diani ${ }^{3}$ \\ ${ }^{1,2,3}$ Program Studi Pendidikan Bahasa dan Sastra Indonesia \\ Jurusan Pendidikan Bahasa dan Seni \\ FKIP Universitas Bengkulu \\ ritayuliutami7037@gmail.com
}

\begin{abstract}
Abstrak
Penelitian ini bertujuan untuk mengetahui penggunaan gaya bahasa siswa kelas VII A SNP N 21 Bengkulu Utara Tahun Ajaran 2016/2017 dalam mendongeng dan untuk mengetahui makna yang terkandung dalam gaya bahasa ketika siswa mendongeng. Penelitian ini merupakan penelitian kualitatif dengan menggunakan pendekatan deskriptif kualitatif. Sedangkan untuk mengkaji makna yaitu dengan menggunkan pendekatan semantik yang digunakan untuk mengkaji makna gaya bahasa siswa kelas VII A SMP N 21 Bengkulu Utara Tahun Ajaran 2016/2017 dalam mendongeng. Berdasarkan hasil analisis data, didapat bahwa; (1) dalam mendongeng siswa kelas VII A SMP N 21 Bengkulu Utara Tahun Ajaran 2016/2017 dalam mendongeng menggunakan gaya bahasa pada saat menyampaikan ceritanya secara langsung ke judul yang akan didongengkan. Dalam penggunaannya, setiap gaya bahasa yang dimanfaatkan memiliki makna tersendiri untuk memperhalus dan memperindah bahasa, terlebih lagi pada pendekatan semantik mengkaji tentang makna yang ditemukan untuk mengacu pada gaya bahasa siswa kelas VII A SMP N 21 Bengkulu Utara Tahun Ajaran 2016/2017 dalam mendongeng.
\end{abstract}

\section{Kata Kunci: Gaya bahasa, mendongeng, siswa kelas VII A SMPN 21 Bengkulu Utara.}

\begin{abstract}
This study aims to determine the use of Gaya Bahasa Siswa Kelas VII A SNP N 21 Bengkulu Utara Tahun Ajaran 2016/2017 Dalam Mendongeng and to know the meaning contained in the style of language when students tell stories. This research is a qualitative research using qualitative descriptive approach. While to study the meaning is by using semantic approach that is used to study the meaning of Gaya Bahasa Siswa Kelas VII A SNP N 21 Bengkulu Utara Tahun Ajaran 2016/2017 Dalam Mendongeng. Based on data analysis, it is found that; (1) in storytelling Gaya Bahasa Siswa Kelas VII A SNP N 21 Bengkulu Utara Tahun Ajaran 2016/2017 Dalam Mendongeng using the style of language at the time convey the story directly to the title to be told. In its use, every style of language utilized has its own meaning to refine and beautify the language, moreover the semantic approach to study the meaning found to refer to the style of Gaya Bahasa Siswa Kelas VII A SNP N 21 Bengkulu Utara Tahun Ajaran 2016/2017 Dalam Mendongeng.
\end{abstract}

Keywords: Style of language, storytelling, students of class VII A SMPN 21 North Bengkulu. 


\section{PENDAHULUAN}

Gaya bahasa yang digunakan untuk mendongengkan suatu cerita pada setiap individu umumnya berbeda-beda, karena dalam mendongeng setiap individu mempunyai cara dan gaya bahasa yang khas dalam berbahasa yang dapat menjadi ciri atau jati diri individu tersebut. Saat mendongeng, gaya bahasa dan pemilihan kata yang indah, dapat menarik perhatian pendengar. Oleh karena itu pendongeng harus pandai dalam mengolah gaya bahasa dan memilih kata karena dapat mempengaruhi makna atau amanat cerita yang peserta didik dongengkan.

Penggunaan gaya bahasa juga berkaitan dengan tingkat kecerdasan dan kreatifitas anak. Jika seorang anak tersebut mempunyai tingkat kecerdasan dan kreatifitas yang tinggi maka anak tersebut akan menggunakan gaya bahasa agar dongeng yang disampaikan menjadi lebih menarik.

Keberhasilan seseorang saat mendongeng sering kali dipengaruhi oleh kemampuan mengolah rangkaian kata menjadi kalimat yang enak didengar dan diterima sebagai bahasa yang memiliki makna. Dengan bahasa manusia dapat berkomunikasi dengan lebih mudah.

Gaya bahasa adalah sebagai cara untuk pengaturan atau rangkaian kata-kata dalam menyatakan individualitas penulis, ide, dan maksud dalam pikirannya (Thrall dan Hibbard, dalam Sukada, 1987:84). Dalam persoalan gaya bahasa, khususnya pada pemilihan kata, dasar yang digunakan untuk menentukan suatu makna sudah berubah atau tidak adalah pemakaian kata dengan makna tertentu harus bersifat rasional. Hal ini dimaksudkan informasi yang disampaikan oleh pendongeng dapat diterima dengan baik oleh pendengar. Dapat dilihat dengan petikan berikut:

"Merak memiliki bulu yang bagus. Jika tersorot sinar matahari bulu-bulu merak itu berkilauan. Kilauannya warna-warni tampak bagai berlian, apabila sedang merentangkan sayapnya, keindahan bulunya begitu sempurna".

Dari kutipan kalimat di atas merupakan jenis gaya bahasa hiperbol karena adanya semacam kata-kata yang melebih-lebihkan suatu pernyataan dengan membesar-besarkan sesuatu hal.

Kutipan di atas menggunakan makna kiasan. Maksud dari makna kiasan adalah semua bentuk bahasa yang tidak merujuk pada arti yang sebenarnya atau sesungguhnya. Hal ini dibuktikan dengan adanya kata-kata kilaunya warna-warni bagaikan berlian yang dimiliki oleh seekor merak.

Hubungan antara gaya bahasa dan kalimat merupakan dua hal yang tidak bisa dipisahkan, kedua hal ini sangatlah berperan penting pada aktivitas mendongeng. Kalimat memiliki peran penting dalam ungkapan-ungkapan yang menggunakan gaya bahasa.

Siswa dalam mendongeng tentunya terkait dengan perkembangan kognitif dan perkembangan bahasanya, yang berarti faktor intelek/kognisi sangat berpengaruh terhadap perkembangan kemampuan dalam berbahasa (Sunarto, 2013:137). Hal ini sangat berpengaruh terhadap mental anak yang baru beranjak remaja. Karena pada saat remaja inilah siswa diasah kemampuan berbicaranya diberbagai kesempatan.

Saddhono (2012:35) menyatakan bahwa berbicara merupakan salah satu alat komunikasi penting untuk dapat menyatakan diri sebagai anggota masyarakat. Dengan kata lain, berbicara dimanfaatkan sebagai alat komunikasi dengan sesama atau lingkungan. Pakar lain juga berpendapat bahwa berbicara adalah kemampuan mengucapkan bunyi-bunyi artikulasi atau kata-kata untuk mengekspresikan, menyatakan, serta 
menyampaikan pikiran, gagasan, dan perasaan (Tarigan, 2006:15).

Mendongeng adalah menurunkan sesuatu yang mengisahkan tentang perbuatan atau sesuatu kejadian dan disampaikan secara lisan dengan tujuan membagikan pengalaman dan pengetahuan kepada orang lain (Sbachir 2005:2 dalam skripsi Rianthi 2010:21).

Kegiatan mendongeng merupakan kegiatan yang sederhana dan mudah. Makna yang terkandung dalam dongeng juga sangat luas, hanya saja dalam pemilihan gaya bahasanya sangat sulit untuk diungkapkan, apalagi yang menyampaikan sebuah dongeng masih dalam pendidikan menengah pertama. Kenyataannya, tidak semua orang mampu mengisahkan kembali cerita tersebut. Mendongeng pun juga memikat dan mendatangkan manfaat bagi para pendengarnya terutama dalam menyampaikan amanat melalui bahasa lisan.

Dongeng merupakan cerita yang tokohnya bisa berupa binatang. Cerita dalam dongeng dianggap tidak benarbenar terjadi atau nyata. Dongeng dahulunya berbentuk sastra lisan dan diceritakan secara turun temurun dari generasi ke generasi berikutnya tanpa meninggalkan amanat dan makna dalam dongeng tersebut. Karena sifatnya yang lisan, maka mendongeng sangat memerlukan gaya bahasa sebagai daya tarik pendengar. Kegiatan mendongeng merupakan cara siswa untuk menyampaikan pesan moral melalui bahasa lisan.

Teori yang digunakan dalam penelitian linguistik ini adalah gaya bahasa dan pendekatan semantik. Keraf (2006:113) menyatakan bahwa gaya bahasa atau style adalah cara mengungkapkan pikiran melalui bahasa secara khas yang mempertimbangkan jiwa dan kepribadian penulis atau pemakai bahasa. Sedangkan menurut Stanton (2007:61) gaya bahasa adalah cara pengarang dalam menggunakan bahasa. Oleh karena itu, gaya bahasa juga disebut cara penulis untuk mengungkapkan pikiran melalui bahasa secara khas dan memperlihatkan jiwa dan kepribadiannya.

Gaya bahasa dibagi menjadi empat yaitu, pertama gaya bahasa berdasarkan pilihan kata, yaitu gaya bahasa resmi, gaya bahasa tak resmi, dan gaya bahasa percakapan; kedua gaya bahasa berdasarkan nada, yang dibagi menjadi gaya sederhana, gaya bahasa mulia dan bertenaga, gaya bahasa menengah; yang ketiga adalah gaya bahasa berdasarkan struktur kalimat yaitu klimaks, antiklimaks, paralelisme, antitesis, dan repetisi, dan gaya bahasa yang terakhir adalah gaya bahasa berdasarkan langsung atau tidaknya makna. Gaya bahasa ini dibagi menjadi dua bagian yaitu gaya bahasa retoris dan gaya bahasa kiasan (Keraf, 2006:116). Gaya bahasa perumpamaan adalah dua hal yang pada hakikatnya berlainan dan yang sengaja kita anggap sama (Tarigan dalam Eka, 2013:12).

Pendekatan semantik adalah suatu pendekatan makna dalam suatu unsur dari sebuah kata atau lebih tepatnya sebagai gejala dalam ujaran. Semantik terdiri dari dua komponen, (1) komponen yang mengartikan, yaitu yang berwujud bentukbentuk bunyi bahasa, dan s(2) komponen yang diartikan atau makna dari yang berwujud bentuk-bentuk bunyi bahasa (Chaer, 2009:2).

Makna denotasi yaitu makna yang wajar, makna yang asli, makna yang muncul pertama, yang diketahui oleh para pemula, makna sebagaimana adanya, makna yang sesuai dengan kenyataan (Parera, 2004:97-98). Makna konotasi adalah makna yang wajar tadi telah memperoleh tambahan perasaan tertentu, emosi tertentu, dan rangsangan tertentu pula yang bervariasi dan tak terduga pula 
(Parera, 2004:98). Makna kias atau kiasan adalah makna sebagai oposisi dari arti sebenarnya. Oleh karena itu, semua bentuk bahasa (baik kata, frasa, maupun kalimat) yang tidak merujuk pada arti sebenarnya (arti leksikal, arti konseptual, atau arti denotatif) disebut mempunyai arti kias atau kiasan (Chaer, 2009:77).

\section{METODE}

Studi ini merupakan bagian dari penelitian deskriptif kualitatif yaitu langkah kerjanya yang berupa untuk mendeskripsikan suatu objek, fanomena, atau setting sosial yang terjewantah dalam suatu tulisan yang bersifat naratif. Artinya data, fakta yang dihimpun berbentuk kata atau gambar daripada angka-angka. Mendeskripsikan sesuatu berarti menggambarkan apa, mengapa, dan bagaimana suatu kejadian terjadi (Komariah \& Satori, 2009:28).

Dalam penelitian ini teknik yang digunakan untuk mengumpulkan data adalah teknik rekam yang dilakukan secara visual. Teknik untuk mendapatkan data dalam penelitian ini dilakukan dengan dua tahap, yaitu (1) rekam adalah dalam teknik rekam ini, data direkam menggunakan alat rekam yang telah disediakan oleh penulis. Ini dilakukan agar data dapat disimpan untuk ditranskrip dengan cara ortografis (Muhammad, 2014:210) dan (2) Transkripsi data digunakan untuk mempermudah langkah selanjutnya yaitu menganalis data.

Dalam penelitian ini menurut Miles dan Huberman dalam Sugiono (2006:337346) mengemukakan bahwa dalam menganalisis data dibagi menjadi 3 tahap, yaitu (i) data reduction (reduksi data), (ii) data display (menyajikan data), dan (iii) conclusion drawing/verification (menarik kesimpulan/verifikasi).

Langkah awal dalam menganalisis data adalah dengan data reduction (reduksi data). Dengan demikian data yang diperoleh adalah dengan cara merekam secara visual kemudian ditranskripsikan dan rekaman data yang tidak terlalu jelas dibuang, sehingga langkah ini akan memberikan gambaran yang jelas kepada penulis dan mempermudah peneliti untuk melakukan pengumpulan data selanjutnya, dan mencarinya bila diperlukan.

$$
\text { Langkah selanjutnya setelah }
$$

reduksi data ialah data display atau menyajikan data. Dalam penelitian kualitatif ini, penyajian data dilakukan dengan bentuk uraian singkat yang disajikan dalam bentuk uraian naratif. Dengan mendisplay data, maka akan memudahkan untuk memahami apa yang terjadi dan merencanakan kerja selanjutnya berdasarkan apa yang telah dipahami.

Langkah yang ke tiga atau yang terakhir dalam analisis data kualitatif ini adalah menganalisis gaya bahasa yang digunakan oleh siswa dalam mendongeng, dan terakhir yaitu penarikan simpulan.

\section{HASIL DAN PEMBAHASAN}

\section{Jenis Gaya Bahasa Yang Digunakan Siswa Kelas VII A SMP N 21 Bengkulu Utara Tahun Ajaran 2016/2017 dalam Mendongeng.}

Dalam berbahasa atau berkomunikasi manusia memanfaatkan bermacam gaya bahasa dalam kehidupannya. Seperti yang diketahui gaya bahasa merupakan penggunaan yang khas dalam sebuah cerita. Penggunaan gaya bahasa tidak hanya sebagai pendukung saja, melainkan gaya bahasa ini dimanfaatkan untuk memunculkan efek keindahan, menghaluskan, dan menyamarkan suatu makna. Begitu pula dengan mendongeng yang tidak bisa terlepas dari pemanfaatan atau pemakaian bermacam ragam gaya bahasa sebagai pendukung alur cerita dan dilengkapi dengan pemilihan bahasa yang indah 
untuk memudahkan pendengar memahami cerita.

Penggunaan Jenis Gaya Bahasa Berdasarkan Langsung Tidaknya Makna (Retoris) Siswa Kelas VII A SMP N 21 Bengkulu Utara Tahun 2016/2017 dalam Mendongeng

Pleonasme dan Tautologi

Pleonasme dan Tautologi gaya bahasa yang mempergunakan kata-kata lebih banyak daripada yang diperlukan untuk menyatakan suatu pikiran atau gagasan. Walaupun secara praktis kedua istilah ini disamakan saja, namun ada yang membedakan keduanya. Dapat dikatakan pleonasme karena semua acuan itu tetap utuh dengan makna yang sama. Sedangkan tautologi kata yang berlebihan itu yang sebenarnya mengandung perulangan dari sebuah kata yang lain (Keraf, 2006: 133). Berikut adalah kutipan yang memanfaatkan gaya bahasa pleonasme siswa kelas VII A SMP N 21 Bengkulu Utara Tahun Ajaran s2016/2017 dalam mendongeng.

\section{Pleonasme}

Data 1.

Bangau pun tergelak dengan terbahakbahak dan berkata "danau itu hanya khayalanku saja dan yang nyata, sekarang engkau akan menjadi makananku yang paling lezat. (dongeng no 14)

Kutipan di atas merupakan gaya bahasa pleonasme yang ditemukan dalam hanya pada data 1 . Pada data 1 di atas menggunakan gaya bahasa pleonasme yang ditunjukkan dengan adanya kata-kata yang mubazir seperti tergelak dan terbahak-bahak. Dalam kutipan di atas dimaksud bahwa $\mathrm{Si}$ bangau itu sangat senang karena mendapat mangsa dengan cara berbohong kepada bangsa ikan. Dirasa tanpa adanya penjelasan terbahakbahak tetapi hanya kata tergelak saja sudah dapat mengerti bahwa itu termasuk rasa senang yang amat sangat.

\section{Tautologi}

Data 2.

Raja di kerajaan itu adalah seorang manusia, nama baginda itu Petani (dongeng no 1)

Kutipan di atas merupakan gaya bahasa tautologi yang hanya ditemukan pada data 1 . Pada data 2 juga memanfaatkan gaya bahasa tautologi yang ditunjukkan dengan adanya perulangan yang berlebihan. Seperti yang terdapat dalam kutipan gaya bahasa tautologi di atas yang menjelaskan kembali bahwa baginda itu adalah seorang raja yang bernama Petani. Sehingga kata baginda tidak perlu diulang, karena sudah cukup dengan raja di kerajaan itu adalah seorang manusia yang bernama Petani.

Penggunaan Jenis Gaya Bahasa Berdasarkan Langsung Tidaknya Makna (Kiasan) Siswa Kelas VII A SMP N 21 Bengkulu Utara Tahun 2016/2017 dalam Mendongeng

Personifikasi atau Prosopopoeia

Gaya bahasa personifikasi atau prosopopoeia semacam gaya bahasa kiasan yang menggambarkan benda-benda mati atau barang-barang yang tidak bernyawa seolah-olah memiliki sifat-sifat manusia. Berikut adalah kutipan yang memanfaatkan gaya bahasa personifikasi atau prosopopoeia siswa kelas VII A SMP N 21 Bengkulu Utara Tahun Ajaran 2016/017 dalam mendongeng.

Data 25.

Gagak hitam tidak kuasa menahan hasratnya, ia pergi dari tempat tinggalnya, ia terbang tak tentu arah dan tujuan. Ia mengembara mencari cara untuk meluluhkan keinginannya menjadi merak. (dongeng no 3) 
Pada data 25 memanfaatkan gaya bahasa personifikasi atau prosopopoeia yang ditunjukkan atau yang ditandai dengan kata hasrat. Maksud dari kata hasrat bukanlah sesuatu keinginan yang negatif, padanannya adalah keinginan untuk harapan yang baik. Selain itu, pilihan kata hasrat adalah kata-kata yang tajam dan tidak seharusnya digunakan pada kutipan tersebut. Karena dalam data 25 ini dimaksud untuk memperjelas keinginan seekor gagak yang berkeinginan menjadi seekor merak yang indah.

Penggunaan Jenis Gaya Bahasa Berdasarkan Struktur Kalimat Siswa Kelas VII A SMP N 21 Bengkulu Utara Tahun 2016/2017 dalam Mendongeng

\section{Repetisi Epizeukis}

Repetisi yaitu pengulangan bunyi, suku kata, kata atau bagian kalimat yang dianggap penting. Gaya bahasa repetisi epizeukis adalah repetisi yang bersifat langsung, artinya kata yang dipentingkan diulang beberapa kali berturut-turut (Keraf, 2006: 127). Berikut adalah kutipan yang memanfaatkan gaya bahasa epizeukis siswa kelas VII A SMP N 21 Bengkulu Utara Tahun Ajaran 2016/1017 dalam mendongeng.

Data 37.

Burung yang bulunya hitam, burung yang paruhnya kuning, burung yang kakinya pendek dan tidak kokoh yang suaranya serak.(dongeng no 3)

Pada data 37 di atas menunjukkan gaya bahasa repetisi epizeukis dengan kata burung yang merupakan pengulangan kata sebagai penegas maksud. Kutipan di atas menjelaskan bahwa yang memiliki ciri-ciri seperti pada data 37 adalah burung gagak.
Penggunaan Jenis Gaya Bahasa

Berdasarkan Nada Kelas VII A SMP N 21

Bengkulu Utara Tahun 2016/2017 dalam

Mendongeng Siswa.

Gaya Menengah

Gaya menengah adalah gaya yang diarahkan kepada usaha untuk menimbulkan suasana senang dan damai. Karena tujuannya adalah menciptakan suasana senang dan damai, maka nadanya juga bersifat lemah lembut, penuh kasih sayang, dan mengandung humor yang sehat (Keraf, 2006: 122). Berikut contoh kutipan gaya bahasa menengah siswa kelas VII A SMP N 21 Bengkulu Utara Tahun Ajaran 2016/2017 dalam mendongeng. Data 45.

"hai, rusa yang baik hati. Aku mendengar keluhanmu, aku tahu permohonnmu tulus. Karena itu aku akan mengabulkannya." Ucap suara bisikan itu.(dongeng no 5)

Data 45 di atas memanfaatkan gaya bahasa menengah diarahkan kepada usaha usaha untuk menimbulkan suasana senang dan damai. Hal ini dibuktikan bahwa sang dewata agung memberikan ketenangan kepada rusa dan akan mengabulkan permohonan rusa, karena rusa dimintai pertolongan oleh sang raja kuda.

Penggunaan Jenis Gaya Bahasa Perumpamaan Siswa Kelas VII A SMP N 21 Bengkulu Utara Tahun 207/2018 dalam Mendongeng

Perumpamaan

Gaya bahasa perumpamaan ini adaah perbandingan dua hal yang pada hakikatnya berlainan dan yang sengaja dianggap sama (Tarigan, 2013: 9). Dalam penggunaannya, gaya bahasa perumpamaan lebih kepada pengibaratan sesuatu agar terlihat lebih bermakna. Berikut contoh kutipan gaya bahasa perumpamaan siswa kelas VII A SMP N 21 Bengkulu Utara Tahun Ajaran 2016/2017 dalam mendongeng. 
Data 46.

Langit cerah, warnanya putih bagaikan salju, dan warna biru bagaikan permadani sutra yang halus. (dongeng no)

Data 46 menggunakan gaya bahasa perumpamaan dengan membandingkan dua hal dianggap sama yang ditunjukkan pada kata langit cerah dengan putih bagaikan salju dan warna biru dengan permadani sutra. Maksud dari kata langit cerah dengan putih bagaikan salju dan warnna biru dengan permadani sutra yaitu membandingkan dua hal dalam satu kalimat yang dianggap sama.

\section{Makna Pada Gaya Bahasa Yang Digunakan Siswa Kelas VII A SMP N 21 Bengkulu Utara Tahun Ajaran 2016/2017 dalam Mendongeng \\ Makna Denotasi}

Makna denotasi yaitu makna yang wajar, makna yang asli, makna yang muncul pertama, yang diketahui oleh para pemula, makna sebagaimana adanya, makna yang sesuai dengan kenyataan (Parera, 2004: 97-98). Berikut adalah kutipan yang memanfaatkan makna denotasi

Data 2.

Raja di kerajaan itu adalah seorang manusia, nama baginda itu Petani (dongeng no 1)

Dalam data 2 di atas menggunakan makna denotasi, karena kata baginda adalah kata yang sesungguhnya seorang raja sebagai adanya atau sesuai dengan kenyataan.

\section{Makna Konotasi}

Makna konotasi adalah makna yang wajar tadi telah memperoleh tambahan perasaan tertentu, emosi tertentu, dan rangsangan tertentu pula yang bervariasi dan tak terduga pula. Makna konotasi ini dapat muncul diantara kata-kata yang bersinonim dan juga konotasi pun dapat muncul pada sebuah kata. Terdapat pula kata-kata tertentu yang berbeda konotasi antarpribadi, antarkelompok masyarakat, antaretnis, dan antargenerasi (Parera, 2004: 98). Berikut adalah kutipan yang memanfaatkan makna konotasi yang digunakan siswa kelas VII A SMP N 21 Bengkulu Utara Tahun Ajaran 2016/2017 dalam mendongeng.

\section{Data 1.}

Bangau pun tergelak dengan terbahakbahak dan berkata "danau itu hanya khayalanku saja dan yang nyata, sekarang engkau akan menjadi makananku yang paling lezat. (dongeng no 14)

Pada data 2 memanfaatkan makna konotasi yang dibuktikan dengan kata tergelak menggunakan makna konotasi, karena pada hakikatnya makna pada kata terbahak-bahak sudah memperoleh tambahan perasaan dan emosi pada si pelaku yaitu seekor bangau.

\section{Makna Kias atau Kiasan}

Makna kias atau kiasan adalah makna sebagai oposisi dari arti sebenarnya. Oleh karena itu, semua bentuk bahasa (baik kata, frasa, maupun kalimat) yang tidak merujuk pada arti sebenarnya (arti leksikal, arti konseptual, atau arti denotatif) disebut mempunyai arti kias atau kiasan (Chaer, 2009: 77). Berikut adalah kutipan yang memanfaatkan makna kias atau kiasan yang digunakan siswa kelas VII A SMP N 21 Bengkulu Utara Tahun Ajaran 2016/2017 dalam mendongeng.

Data 13.

Perubahan kehidupan yang jauh dari rasa nyaman dari kerajaan itu diakibatkan oleh ulah si bebek yang jago bergosip. (dongeng no 13)

Makna yang digunakan pada data 13 merupakan makna kiasan yaitu yang ditunjukkan dengan kata jauh dari rasa nyaman. Maksud dari kata jauh dari rasa nyaman adalah adanya perasaan atau prasangka tertentu yang muncul secara tak 
terduga telah dirasakan pada lingkungan tempat tinggal hewan. Situasi seperti ini yaitu yang diakibatkan oleh ulah bebek yang suka menggunjing hewan lainnya.

\section{PENUTUP}

\section{Kesimpulan}

Kegiatan dalam mendongeng ini membantu siswa mengasah kemampuannya dalam menggunakan gaya bahasa. Siswa menyampaikan dongeng dengan cara terstruktur. Terstruktur yang dimaksudkan adalah terdapat bagian awal, bagian isi, dan bagian akhir.Pada penelitian yang dilaksanakan di SMP N 21 Bengkulu Utara penulis menemukan beberapa gaya bahasa yaitu seperti gaya bahasa berdasarkan pilihan kata (gaya bahasa tak resmi), gaya bahasa berdasarkan pilihan nada (gaya menengah), gaya bahasa berdasarkan struktur kalimat (klimaks, paralase, repetisi, dan antitesis), gaya bahasa berdasarkan berdasarkan langsung tidaknya makna (retoris dan kiasan), dan gaya bahasa perumpamaan.

Makna yang digunakan oleh siswa kelas VII A SMP N 21 Bengkulu Utara Tahun Ajaran 2016/2017 dalam mendongeng adalah makna denotasi, makna konotasi, dan makna kiasan. Setiap gaya bahasa memiliki makna tersendiri untuk memperjelas dan memperindah bahasa. Pendekatan semantik di sini merupakan pendekatan yang menekankan pada makna yang mengacu pada kegiatan mendongeng. Pendekatan semantik digunakan untuk mengatahui maksud atau makna yang terkandung pada gaya bahasa.

\section{Saran}

Saran yang dapat penulis berikan bagi pembaca dan peneliti selanjutnya bahwa kegiatan mendongeng siswa kelas VII A SMP N 21 Bengkulu Utara Tahun Ajaran 2016/2017 dalam mendongeng dapat dijadikan sebagai salah satu metode pembelajaran Bahasa Indonesia di SMP.
Gaya bahasa yang ditemukan dalam penelitian ini dapat dijadikan sebagai sumber materi bahan ajar Bahasa Indonesia. Dengan demikian diharapkan siswa dapat mengambil nilai-nilai pendidikan yang terkandung di dalamnya dan dapat menerapkannya dalam kehidupan sehari-hari.

\section{DAFTAR PUSTAKA}

Chaer, Abdul. 2009. Pengantar Semantik Bahasa Indonesia. Jakarta: Rineka Cipta.

Eka, Eervinda Putri A. "Gaya Bahasa Dalam Acara Silet Di RCTI". Skripsi. Pada Universitas Bengkulu. 2015. Naskah Tidak Publikasi.

Keraf, Gorys. 2006. Dikisi dan Gaya Bahasa. Jakarta: PT Gramedia, Anggota IKAPI.

Komariah, Ahmad \& Satori D. 2009. Metodologi Penelitian Kualitatif. Bandung: Alfabeta.

Muhammad. 2014. Metode Penelitian Bahasa. Jogjakarta: Ar-ruzz Media.

Parera. D. J. 2004. Teori Semantik. Jakarta: Erlangga.

Rianthi, K. "Peningkatan Kemampuan Menulis Melalui Mendongeng". Skripsi. Pada Universitas Indonesia 2010. Naskah Publikasis.

Saddhono, Kundharu \& St. Y. Slamet. 2012. Meningkatkan Kemampuan Berbahasa Indonesia (Teori dan Aplikasi). Bandung: CV. Karya Putra Darwati. 
Stanton, Robert. 2007. Teori fiksi Robert Stanton. Yogyakarta: Pustaka Pelajar.

Sugiono. 2006. Metode Penelitian Pendidikan. Bandung: Alfabeta, Anggota IKAPI.

Sukada, Made. 1987. Pembinaan Kritik Sastra Indonesia

Masalah
Sistematika Analisis Struktur. Bandung:Angkasa ANGGOTA IKAPI.

Sunarto, \& Agung Hartono. 2013. Perkembangan Peserta Didik. Jakarta : Rineka Cipta.

Tarigan, Henri Guntur. 1981. Berbicara Sebagai Suatu Keterampilan Berbahasa. Bandung: Angkasa. 